\title{
Menthol Cough Drops: Cause for Concern?
}

\author{
Danika Johnson, BS, Robert Mead, FAAFP, Korey Kennelty, PharmD, MS, PhD, BCGP, \\ and David Hahn, MD, MS
}

Background: Over-the-counter (OTC) cough remedies are lightly regulated and their potential side effects may go unrecognized. During 2015, over 282 million cough drops were sold in the United States. A Wisconsin community clinician (RM) made clinical observations suggesting that excessive use of OTC cough drops may exacerbate rather than benefit coughs. The goal of this project was to assess whether menthol in cough drops is related to worse cough symptoms.

Methods: From April 2016 through May 2017, 5 Wisconsin primary care clinics invited adolescent and adult outpatients seeking medical care for an acute or subacute cough to take a voluntary, anonymous, 10-question cough drop use survey that included age, sex, smoking status, cough severity, cough duration, and cough drop use (including type and amount).

Results: Of the 548 surveys collected and analyzed, $363(66.2 \%)$ reported using cough drops. Cough drop use was significantly associated with longer duration of cough at presentation $(P<.001)$ but not with overall cough severity $(P=.09)$. Of cough drop users, $269(90 \%)$ reported consuming drops with menthol. Univariate analysis found no statistically significant differences between the menthol and nonmenthol groups for either severity $(P=.65)$ or duration $(P=.17)$. However, significant independent associations were found between cough severity and 1$)$ average menthol dose per cough drop $(R=$ $0.19 ; P=.007), 2)$ number of cough drops consumed daily $(\mathrm{R}=0.2 ; P=.002)$ and 3$)$ total amount of menthol consumed per day $(R=0.21 ; P=.001)$ that remained significant $(P=.003)$ after controlling for age, sex, smoking status, season, and clinic site.

Conclusions: Cough severity in some individuals may be negatively influenced by the amount of menthol consumed via cough drops. Clinicians should include cough drop use in history taking of patients with persisting cough illnesses. Further research into potential mechanisms is warranted. (J Am Board Fam Med 2018;31:183-191.)

Keywords: Cough, Medical History Taking, Menthol, Over-the-Counter Drugs, Primary Health Care, Wisconsin

\section{Clinical Observation}

MS is a 55 -year-old nonsmoking male patient who presented to RM's office in December with a 3-and-a-half-week cough that started with typical upper respiratory infection (URI) symptoms in-

This article was externally peer reviewed.

Submitted 5 September 2017; revised 1 December 2017; accepted 2 December 2017.

From the University of Wisconsin School of Medicine \& Public Health, Madison, WI (DJ); Department of Primary Care, Bellin Health System, Green Bay (RM); College of Pharmacy, University of Iowa, Iowa City, IA (KK); Department of Family \& Community Medicine, University of Wisconsin School of Medicine \& Public Health, Madison (DH).

Funding: This work received in-kind support from the Wisconsin Research \& Education Network (WREN). Conflict of interest: none declared.

Corresponding author: David Hahn, MD, MS, 1100 Delaplaine Court, Madison, WI 53715 (E-mail: dlhahn@wisc. edu). cluding a low-grade fever, malaise, and sore throat that progressed to rhinorrhea and eventually a dry cough. At the time of his office visit only the persistent cough remained, characterized as nonproductive, frequent, and aggravated by talking, with a "tickle" and slight throat discomfort. He had been seen in an urgent care center about 1 week ago and was prescribed azithromycin and an albuterol inhaler, but the cough did not improve. The patient denied taking any OTC medications; however when asked specifically about cough drops he readily admitted to taking up to 10 to 12 menthol-containing cough drops per day for the past 2 weeks. The menthol-containing cough drops relieved the cough temporarily but soon after finishing a lozenge his cough returned. The patient's vital signs, physical examination, chest radiograph and 
spirometry before and after inhaled bronchodilator (ie, albuterol) were normal. RM recommended to the patient to discontinue cough drops and offered no other therapy. Four days later his cough had completely resolved.

\section{RM Narrative}

A persistent cough is a frequent presenting symptom in my practice, especially during the winter months. I often do not have much to offer other than reassurance as there is little supporting evidence for effective treatments. I started asking my patients about use of OTC medications and found they often failed to mention cough drops and other lozenges (as if they felt if they did not actually swallow it then it was not a medication). I started asking specifically about cough drops and was astonished by the number and frequency of cough drops patients were using: up to a bag (20) per day for a couple of weeks. I wondered whether these cough drops somehow played a role in prolonging cough so I began advising patients to discontinue the cough drops and often saw an apparent improvement or resolution in their cough. I speculated that the menthol in cough drops was causing a rebound effect much like decongestants in nasal sprays cause rebound nasal congestion. How could I study this? I contacted the Wisconsin Research and Education Network to see if they could help me shed light on this potential association of mentholated cough drops and a persistent uncomplicated cough in healthy individuals. -RM (J Am Board Fam Med 2018;31:183-191.)

\section{Introduction}

Over-the counter (OTC) medications are used frequently for treatment of cough and cold in the United States. In 2016, over 8 billion dollars were spent on OTC medications to treat upper-respiratory symptoms. ${ }^{1}$ With such substantial use of OTC medications, one would expect considerable evidence supporting their efficacy. However, a Cochrane review published in 2014 found that there was insufficient evidence to either support or negate the use of OTC medications for the treatment of cough and cold. ${ }^{2}$ The limited available evidence suggests that side effects of OTC cough remedies may be underrecognized. Menthol (also known as mint camphor) is a cyclic monoterpine alcohol with analgesic, antifungal, antipruritic, anti-inflammatory, antitussive, antiviral, and insecticidal activities. ${ }^{3}$ Menthol is toxic in high doses. $^{3-5}$ Vicks VapoRub, a popular OTC mentholcontaining medication, has beneficial effects on cough in children ${ }^{6}$ but also has negative effects on respiratory function in some individuals. ${ }^{7}$ Menthol is a common ingredient used in OTC cough drops and lozenges.

Based on the clinical observations and hypotheses presented above we designed a survey aimed at primary-care adolescent and adult outpatients with acute and subacute cough illnesses. The goals of our study were to assess 1) the prevalence of use of OTC cough drops, and 2) whether menthol in cough drops is associated with worse cough symptoms.

\section{Methods}

We distributed a voluntary, anonymous, 10-item survey documenting age, sex, smoking, cough duration and severity, and OTC cough drop use to adolescent and adult primary care outpatients with a chief complaint of cough (Appendix). We recruited patients from 5 rural, suburban, and urban Wisconsin primary-care clinic members of the Wisconsin Research and Education Network (WREN) from April 2016 through May 2017. We instructed clinics to administer the survey only once per patient and to include only patients 13 years of age and older and only those presenting with either an acute or subacute cough (defined as a cough duration $\leq 56$ days). ${ }^{8}$ We limited analyses to these age/duration categories. The University of Wisconsin School of Medicine and Public Health Institutional Review Board reviewed the protocol and declared it exempt.

\section{Analysis}

Descriptive statistics are presented as proportions (categorical variables) or as mean, SD (continuous, normally distributed), or median, 25th to 75th percentile (continuous, non-normally distributed and ordinal). We used Fisher's exact test when comparing $2 \times 2$ tables of categorical variables and the $\chi^{2}$ test when comparing $2 \times(\mathrm{n}>2)$ tables. We used the unpaired $t$-test for comparing the means of normally distributed continuous data and the Kruskal-Wallis test for nonnormally distributed continuous data including ordinal data. We performed linear regression and Spearman Rank Correlation when testing for significant associations between cough duration or cough severity and menthol dose and we controlled for age, sex, smoking, clinic site, and season using 


\begin{tabular}{|c|c|c|c|c|}
\hline & $\begin{array}{l}\text { Cough Drop Users } \\
(\mathrm{N}=363)\end{array}$ & $\begin{array}{l}\text { Cough Drop Nonusers } \\
(\mathrm{N}=184)\end{array}$ & $\begin{array}{c}\text { Total } \\
(\mathrm{N}=548)\end{array}$ & $P$-Value ${ }^{\dagger}$ \\
\hline \multicolumn{5}{|l|}{ Sex } \\
\hline Male, n (\%) & $114(31.8)$ & $73(39.9)$ & $188(34.6)$ & \multirow[t]{2}{*}{.07} \\
\hline Female, n (\%) & $245(68.2)$ & $114(60.1)$ & $355(65.4)$ & \\
\hline Age (years), mean (SD) & $50.2(18.2)$ & $48.2(18.6)$ & $49.5(18.3)$ & .25 \\
\hline \multicolumn{5}{|l|}{ Smoking status } \\
\hline Current smoking, n (\%) & $50(14)$ & $28(15.3)$ & $78(14.4)$ & \multirow[t]{3}{*}{.91} \\
\hline Past smoking, n (\%) & $99(27.7)$ & $51(27.9)$ & $150(27.7)$ & \\
\hline Never smoking, n (\%) & $208(58.3)$ & $104(56.8)$ & $313(57.8)$ & \\
\hline $\begin{array}{l}\text { Cough severity ( } 7 \text {-point ordinal scale), } \\
\text { median ( } 25 \text { th to } 75 \text { th percentile) }\end{array}$ & $6(4$ to 6$)$ & $5(4$ to 6$)$ & $6(4$ to 6$)$ & .09 \\
\hline \multicolumn{5}{|l|}{ Severity category, n (\%) } \\
\hline Very mild & $3(0.8)$ & $4(2.2)$ & $7(1.3)$ & \multirow[t]{7}{*}{.052} \\
\hline Mild & $27(7.5)$ & $16(8.7)$ & $43(7.9)$ & \\
\hline Mild/moderate & $2(0.6)$ & $2(1.1)$ & $4(0.7)$ & \\
\hline Moderate & $100(27.6)$ & $67(36.6)$ & $167(30.6)$ & \\
\hline Moderate/severe & $32(8.8)$ & $6(3.3)$ & $38(7.0)$ & \\
\hline Severe & $151(41.7)$ & $64(34.9)$ & $216(39.6)$ & \\
\hline Very severe & $47(13.0)$ & $24(13.1)$ & $71(13.0)$ & \\
\hline Cough duration (days), mean (SD) & $12.5(9.7)$ & $9.8(8.6)$ & $11.5(9.4)$ & $<.0001$ \\
\hline \multicolumn{5}{|l|}{ Clinic, No. respondents (\%) } \\
\hline A (urban) & $165(45.5)$ & $71(38.6)$ & $236(43.1)$ & \multirow[t]{5}{*}{.13} \\
\hline B (rural) & $152(41.9)$ & $79(42.9)$ & $232(42.3)$ & \\
\hline C (inner city) & $30(8.3)$ & $16(8.7)$ & $46(8.4)$ & \\
\hline $\mathrm{D}$ (rural) & $7(1.9)$ & $8(4.3)$ & $15(2.7)$ & \\
\hline E (suburban) & $9(2.5)$ & $10(5.4)$ & $19(3.5)$ & \\
\hline
\end{tabular}

${ }^{*}$ Discrepancies within and between categories are due to missing data and/or round-off errors.

${ }^{\dagger}$ Users versus Nonusers.

$\mathrm{SD}$, standard deviation.

multivariate ANOVA modeling. Results are reported as significant if $P<.05$.

The survey contained 5 categories for cough severity (Appendix) but several respondents checked 2 adjacent categories (eg, some checked both mild and moderate, and others checked both moderate and severe); thus we created 2 additional categories (Mild/moderate and moderate/severe). We present this 7-category scale (there were no significant differences between analyses using the 5- and the 7 -point scales). Cough drops were categorized by brand and type. In cases where marketed types could have contained varying amounts of menthol we assigned the midrange value. Some respondents reported taking both menthol- and nonmenthol-containing cough drops. They were included in the Menthol group. Cases that could not be unambiguously assigned a value for the amount of menthol consumed daily were excluded from those analyses.

\section{Results}

\section{Baseline Characteristics}

A total of 638 surveys were collected. Sixty (9\%) reported on children 12 years or younger; $30(5 \%)$ reported cough durations greater than 56 days. Table 1 presents the patient characteristics of the remaining 548 eligible respondents. Both urban and rural primary-care populations are represented. The study group was mostly middle aged, two thirds were female, and the majority had never smoked. Two thirds of respondents (66.2\%) reported using cough drops. Cough-drop users and cough-drop nonusers were similar in demographic characteristics (sex, age, smoking status). Cough drops users tended to rate their coughs as more severe than nonusers but this difference was not statistically significant. Reported duration of the cough illness was significantly greater in cough-drop users compared with nonusers (Table 1). 
Table 2. Cough Drop Users: Menthol Versus Nonmenthol Comparisons*

\begin{tabular}{|c|c|c|c|}
\hline & Menthol $(\mathrm{N}=269)$ & Nonmenthol $(\mathrm{N}=31)$ & $P-$ Value $^{\dagger}$ \\
\hline $\begin{array}{l}\text { Cough severity ( } 7 \text {-point ordinal scale), } \\
\text { median ( } 25 \text { th to } 75 \text { th percentile) }\end{array}$ & $6(1$ to 7$)$ & $6(2$ to 7$)$ & .65 \\
\hline \multicolumn{4}{|l|}{ Severity category, n (\%) } \\
\hline Very mild & $0(0.0)$ & $2(0.8)$ & .80 \\
\hline Mild & $18(6.8)$ & $2(6.5)$ & \\
\hline Mild/moderate & $2(0.8)$ & $0(0.0)$ & \\
\hline Moderate & $72(27.1)$ & $12(38.7)$ & \\
\hline Moderate/severe & $25(9.4)$ & $1(3.2)$ & \\
\hline Severe & $111(41.7)$ & $12(38.7)$ & \\
\hline Very severe & $36(13.5)$ & $4(12.9)$ & \\
\hline Duration (days), mean (SD) & $13.1(9.9)$ & $10.7(9.1)$ & .17 \\
\hline \multicolumn{4}{|l|}{ Cough Drops } \\
\hline \multicolumn{4}{|l|}{ No. Days Used, n (\%) } \\
\hline 0 to 3 days & $85(32.0)$ & $13(41.9)$ & .36 \\
\hline 4 to 7 days & $79(29.7)$ & $12(38.7)$ & \\
\hline 8 to 10 days & $40(15.0)$ & $2(6.5)$ & \\
\hline 11 to 14 days & $16(6.0)$ & $1(3.2)$ & \\
\hline $14+$ days & $46(17.3)$ & $3(9.7)$ & \\
\hline \multicolumn{4}{|l|}{ No. used per day, n (\%) } \\
\hline 0 to 5 & $163(61.7)$ & $17(54.8)$ & .73 \\
\hline 6 to 10 & $68(25.8)$ & $9(11.7)$ & \\
\hline 11 to 15 & $23(8.7)$ & $3(9.7)$ & \\
\hline 16 to 20 & $8(3.0)$ & $1(3.2)$ & \\
\hline $20+$ & $2(0.8)$ & $1(3.2)$ & \\
\hline \multicolumn{4}{|l|}{ Daily menthol dose (mg) } \\
\hline Mean (SD) & $23.1(22.0)$ & 0.0 & - \\
\hline Range & 1.1 to 117.9 & 0.0 to 0.0 & \\
\hline
\end{tabular}

*Discrepancies within and between categories are due to missing data and/or round-off errors.

${ }^{\dagger}$ Menthol versus Nonmenthol.

$\mathrm{SD}$, standard deviation.

\section{Menthol Use Versus Nonuse}

Sixty-three cough drop users (17\%) provided insufficient information on cough drop type to definitively categorize them as menthol containing or not. Table 2 presents results for the remaining 300 cough drop users (83\%), 269 (90\%) of whom reported using cough drops containing menthol. Analysis showed no statistically significant differences between the menthol and nonmenthol groups for either cough severity or cough duration at presentation (Table 2).

\section{Menthol Dose Response}

For the group of cough drop users $(\mathrm{n}=300)$ for whom we could ascertain menthol category (ie, menthol-containing vs menthol-noncontaining cough drops, and menthol dose) we analyzed associations of cough severity and cough dura- tion with 1) the number of cough drops consumed per day, 2) the average cough drop menthol content, and 3) the total daily dose of menthol consumed (calculated as the average menthol dose per cough drop $\times$ the number of cough drops consumed daily). The number of drops per day was reported in ascending categories (see Table 2). We present the analysis using the number of drops per day as an ordinal variable. A comparable analysis using the mean value for each category did not significantly affect the results (data not shown). We present tests of association including nonmenthol-containing cough drops (ie, menthol dose $=0$ ). Excluding nonmenthol cough drops did not significantly affect the results (data not shown). Univariate analyses found significant correlations between cough severity and the number of cough drops 
Figure 1. Regression of cough severity ( $y$-axis: ordinal 7-point scale ranging from very mild $=1$ to very severe $=$ 7) against menthol dose $(\mathrm{mg})$ consumed per day in cough drops (x-axis). The slope of the regression line is significantly different from zero $(P=.001)$ with a Spearman Rank correlation coefficient of 0.21 .

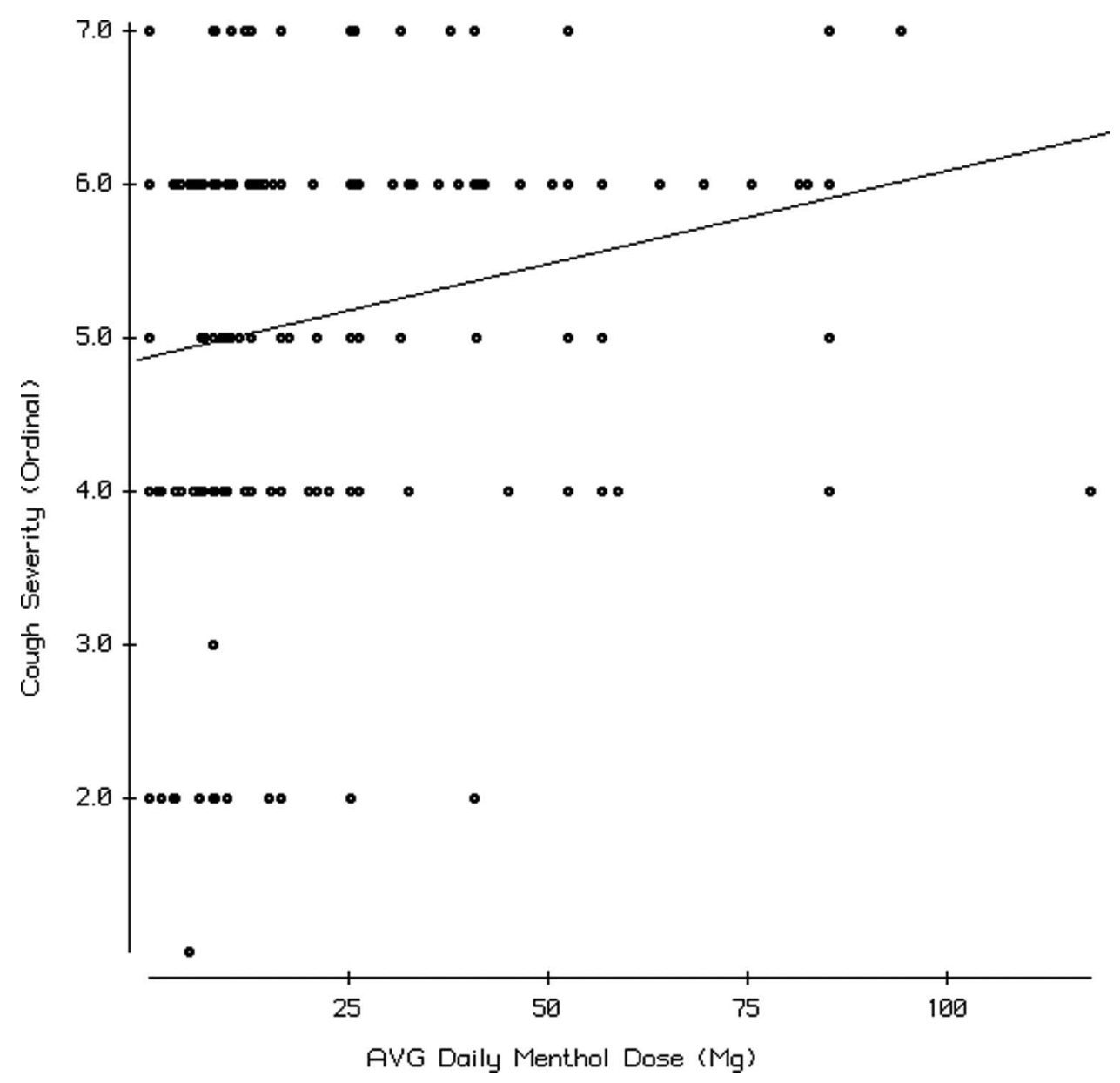

used per day ( $\mathrm{R}=0.2 ; P=.002)$ and the average menthol dose per cough drop $(\mathrm{R}=0.19 ; P=$ .007). Both these associations remained significant in multivariate models controlling for age, sex, smoking, season, and clinic $(P<.0001$ for use and $P=.003$ for dose, respectively). We also analyzed use and dose in a combined model controlled for age, sex, smoking, season, and clinic and found that both variables remained significantly associated with cough severity $(P=.002$ for use and $P=.02$ for dose, respectively). We then multiplied daily number by average dose to create a variable representing the relative amounts of menthol consumed per day. We found a significant correlation with cough severity and menthol dose per day $(\mathrm{R}=0.21 ; P=$ $.001)$ that remained significant $(P=.003)$ after controlling for age, sex, smoking status, season, and clinic site (Figure 1). Comparable analyses for cough duration did not show significant associations.

\section{Discussion}

Based on the clinical observations of 1 of the authors (RM) we sought to determine the prevalence of use of cough drops and to investigate whether exposure to menthol in cough drops would be associated with self-reported cough severity. We found that two thirds of this primary-care population drawn from geographically diverse populations in Wisconsin reported using cough drops for acute and subacute coughing illnesses, and a large majority $(90 \%)$ of the cough drops contained varying amounts of menthol. Given the large amounts of cough drops sold and presumably consumed in the United States, these data are not surprising. ${ }^{1} \mathrm{We}$ hypothesized a priori that cough drop consumption 
would be associated with both duration and severity of cough (ie, the sicker the patients felt or the longer they suffered, the more likely they would be to seek relief from OTC medications, including cough drops). The positive associations we found between using cough drops, illness duration and severity are consistent with our expectations but not informative regarding menthol effects on cough severity.

Some individuals with cough may seek out high doses of menthol in cough drops. We do not have direct evidence about the prevalence of such menthol-seeking behavior but we suspect that it is not common. We hypothesized a priori that most patients with cough would not seek out cough drops with higher menthol doses. Therefore, positive associations between menthol dose and cough severity could be interpreted as supporting the hypothesis that menthol might contribute to illness severity, at least in some cases. We found significant positive associations of cough severity with the number of menthol-containing cough drops consumed per day, the average menthol dose per cough drop, and the total daily menthol dose consumed via cough drops. All these associations remained significant after controlling for the available covariates. The association of cough severity with number of cough drops consumed per day is expected on the basis that people with more severe coughs would take more cough drops. However, the finding that the menthol dose in a single cough drop was also associated with cough severity, irrespective of the number consumed daily, is an unanticipated finding unless one assumes that people with more severe cough purposefully seek out cough drops with higher menthol contents. We suggest that this menthol-seeking behavior is implausible and that these data support the hypothesis that menthol may have deleterious effects on cough in some cases. What might the mechanism(s) be?

Physiologic studies find that acute exposure to inhaled menthol can raise the cough threshold. ${ }^{9-11}$ These findings are consistent with the acute effects of menthol-containing cough drops on alleviating cough. There is a lack of empirical evidence for menthol increasing cough severity. Acute effects on cough suppression do not rule out the possibility that repeated exposure could cause rebound cough (tachyphylaxis-analagous to neosynephrine rebound nasal congestion) that is 1 potential mecha- nism to explain our findings. We found no studies of repeated or chronic menthol exposure on the human cough reflex. Could chronic or repeated menthol exposure produce rebound cough or otherwise produce adverse clinical effects? In an animal model, trachea specimens exposed to $200 \mathrm{mg}$ of menthol increased mucin secretion and decreased ciliary beat frequency. ${ }^{7}$ We documented average daily menthol doses up to $100 \mathrm{mg}$ that cumulatively would far exceed the dose used in this study (Figure 1). Our results justify further human physiologic studies into possible adverse effects on cough of repeated and/or chronic exposure to menthol, particularly in high doses.

\section{Limitations}

This study has several limitations. Our survey did not include clarification of cough drop flavors within brands. Given that different brand flavors sometimes contained differing amounts of menthol, we averaged the menthol dose in ambiguous situations. We did not address underlying cough etiology, concomitant medications, or potential confounding factors (eg, reflux, allergy, ACE-inhibitor use, other medications that can induce cough). Future epidemiologic studies of mentholcontaining cough drops should at a minimum distinguish at the level of menthol content rather than brand and examine comorbidities and medications. Our results apply to adolescents and adults with clinically acute or subacute cough. Studies of menthol use in chronic cough may be appropriate. We sampled 5 primary care clinics in Wisconsin. Although we included urban, suburban, and rural clinics, we cannot exclude the possibility that prevalence of menthol cough drop use and/or adverse effects may be different in different settings or in other regions. The small number of nonmentholated cough drop users may have limited our power to detect associations of menthol containing cough drops with cough severity. There may be other ingredients in cough drops that also contribute. Lastly, the cross-sectional design precludes conclusions about cause and effect.

\section{Conclusions}

Clinical observations by 1 of the authors (RM) suggested that excessive cough drop consumption might contribute to cough severity. Our cross-sectional observational study found a high prevalence 
of menthol-containing cough drop use in acute and subacute coughing illnesses and significant associations of increasing menthol exposure via cough drops with cough severity. Clinical practice guidelines on chronic unexplained cough do not include a recommendation to rule out cough drop ingestion as a potential cause. ${ }^{12,13} \mathrm{We}$ recommend including a history of OTC cough drop use in the clinical evaluation of severe and/or persistent unexplained cough. A trial of cessation of use may be warranted in cases of excessive or prolonged menthol-containing cough drop consumption before referral for an evaluation of unexplained chronic cough. Because of the extensive use of cough drops for the treatment of cold symptoms in the United States, we advocate future investigations into possible negative side effects of mentholated cough drops.

We wish to thank the clinicians, staff, and patients at the following clinics for their support and participation: Ascension Medical Group at Greenville, Greenvile, WI; Aurora Sinai Family Care Center \& Aurora St. Luke's Family Practice Center, Milwaukee, WI; Bellin Health Ashwaubenon, Green Bay, WI; Mile Bluff Medical Center, Mauston, WI; and Richland Medical Center, Richland Center, WI.

To see this article online, please go to: http://jabfm.org/content/ 31/2/183.full.

\section{References}

1. Consumer Healthcare Products Association. Available from: https://www.chpa.org/OTCsCategory. aspx. Accessed on August 20, 2017.

2. Smith SM, Schroeder K, Fahey T. Over-the-counter (OTC) medications for acute cough in children and adults in community settings. Cochrane Database Syst Rev 2014;CD001831.

3. Kamatou GP, Vermaak I, Viljoen AM, Lawrence BM. Menthol: A simple monoterpene with remarkable biological properties. Phytochemistry 2013;96: 15-25.

4. Menthol. Available from: http://en.wikipedia.org/ wiki/Menthol. Accessed on August 20, 2017.

5. Baibars M, Eng S, Shaheen K, Alraiyes AH, Alraies MC. Menthol toxicity: An unusual cause of coma. Case Rep Med 2012;2012:187039.

6. Paul IM, Beiler JS, King TS, et al. Vapor rub, petrolatum, and no treatment for children with nocturnal cough and cold symptoms. Pediatrics 2010;126: 1092-9.

7. Abanses JC, Arima S, Rubin BK. Vicks VapoRub induces mucin secretion, decreases ciliary beat frequency, and increases tracheal mucus transport in the ferret trachea. Chest 2009;135:143-8.

8. Irwin RS, Baumann MH, Bolser DC, et al. Diagnosis and management of cough executive summary: ACCP evidence-based clinical practice guidelines. Chest 2006;129(1 Suppl):1S-23S.

9. Laude EA, Morice AH, Grattan TJ. The antitussive effects of menthol, camphor and cineole in conscious guinea-pigs. Pulm Pharmacol 1994;7:179-84.

10. Morice AH, Marshall AE, Higgins KS, Grattan TJ. Effect of inhaled menthol on citric acid induced cough in normal subjects. Thorax 1994;49:1024-6.

11. Wise PM, Breslin PA, Dalton P. Sweet taste and menthol increase cough reflex thresholds. Pulm Pharmacol Ther 2012;25:236-41.

12. Gibson P, Wang G, McGarvey L, et al. Treatment of unexplained chronic cough: CHEST guideline and expert panel report. Chest 2016;149:27-44.

13. Pratter MR. Unexplained (idiopathic) cough: ACCP evidence-based clinical practice guidelines. Chest 2006;129(1 Suppl):220S-221S. 
The Wisconsin Research \& Education Network (WREN) at UW-Madison is doing a research study about cough drop use. We invite you to participate in this study because you are seeking care because of your cough. If you choose to be in the study, we ask that you complete the short survey below, which will take about 2-3 minutes to complete. The survey will help us learn more about cough drop use. You can skip any survey questions that you do not want to answer. Even if you start the survey, you are not required to complete it. You can stop at any time. The survey is anonymous, and no one will be able to link your answers back to you. Please do not include your name or other information that could be used to identify you in the survey responses. Being in this study is voluntary. Please contact Dr. David Hahn at (608) 234-3212 or dlhahn@wisc.edu with questions about this study.

1) What is today's date?

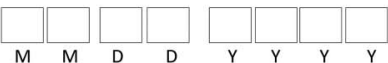

2) About how many days have you had this cough?

3) On average, how bad has your cough been?
$\square$ Very Mild
$\square$ Mild
$\square$ Moderate
$\square$ Severe
$\square$ Very Severe

4) Since this cough began, have you used ANY cough drops or throat lozenges for this cough?

$\square$ No $\longrightarrow$ Go to $\underline{\text { Question } 8}$ below

$\square$ Yes

5) On about how many days have you used cough drops or throat lozenges for this cough? $\square$ 0-3 days

$\square$ 4-7 days

$\square$ 8-10 days

$\square$ 11-14 days

$\square$ 14+ days

6) On days you used cough drops or throat lozenges, how many lozenges or drops did you use per day on average?

$\square 0-5$

$\square 6-10$

$\square$ 11-15

$\square$ 16-20

$\square 20+$

7) Which of the following brands of cough drop/lozenge have you taken for this cough?

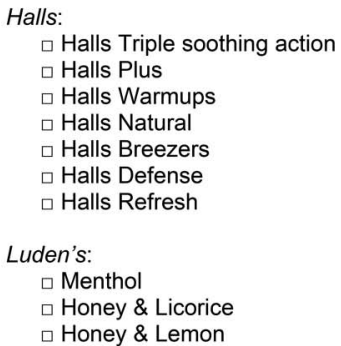

The last few questions are about you:

8) How old are you? 
9) Which of the following best describes your smoking behavior?

$\square$ Never smoked

$\square$ Currently smoking

$\square$ Quit smoking less than 6 months ago

$\square$ Quit smoking more than 6 months ago

10) What is your gender?

$\square$ Male

$\square$ Female

Thank you very much for taking this survey!

PLEASE DROP THIS SURVEY OFF AT THE FRONT DESK AS YOU LEAVE 